\title{
IDENTIFIKASI SOAL TES UTS DAN UAS MATA PELAJARAN BIOLOGI BERDASARKAN TAKSONOMI BLOOM REVISI ANDERSON TERHADAP PEMAHAMAN KONSEP PEMBELAJARAN
}

\author{
Ryan Humardani Syam Pratomo dan Sri Mukminati Nur \\ STKIP Pembangunan Indonesia Makasar, Indonesia \\ Email: ryanhumardani01@gmail.com dan srimukminati07@gmail.com
}

\section{Abstract}

This study aims to measure the level diffculty, and quality of the items in terms of cognitive level based on Anderson's revised bloom taxonomy for midterm (UTS) and final exam questions (UAS) in class X SMA ittihad Makassar. The research sample was midterm (UTS) and final exam questions (UAS) in biology subjects based on Anderson's revised bloom taxonomy in class X IPA SMA ittihad Makassar. Data collection techniques were documentation, interviews, questionnaires and UTS and UAS test questions. The instrument used was a cognitive level based on Anderson's revised Bloom's taxonomy. The research data were analyzed quqlitatively and quantitatively. Based on the results of the quantitative analysis, it can be seen that the difficulty level of class $X$ questions is $71 \%$ of the questions are in the medium category and $29 \%$ of the questions are in the easy category. The result of the research in grouping the questions based on the cognitive domain, for essay questions were dominated by cognitive levels $C 1$ and $C 2$. The result of the qualitatived analysis showed that the questions of UTS and UAS class X IPA at SMA ittihad Makassar in terms of cognitive level, the question based on Anderson's revision of Bloom's taxonomy were not very good, because most of the items, both UTS and UAS question the cognitive level was only between C1,C2 and C3. The findings of this study indicate that the teachers are still unequal in making questions based on the cognitive domain of bloom's taxonomy on UTS and UAS biology questions. This is because the teachers at SMA ittihad Makassar only imitate questions from daily textbook without considering the number of questions in each domain C1, C2, C3, C4, C5 and C6.

Keywords: difficulty level; problem cognitive level; anderson revised bloom's taxonomy

\footnotetext{
Abstrak

Tujuan dari penelitian ini adalah untuk mengukur tingkat kesulitan dan kualitas proyek berdasarkan masalah tingkat kognisi berdasarkan klasifikasi Bloom revisi UTS dan UAS oleh Anderson dari SMA Ittihad Makassar kategori X. Sampel penelitian didasarkan pada metode klasifikasi kelas X IPA SMA Ittihad Makassar Bloom revisi Anderson untuk soal tes UTS dan UAS pada topik biologi. Teknik pengumpulan data adalah dokumentasi, wawancara, angket dan soal tes UTS dan UAS. Instrumen yang digunakan adalah tingkatan kognitif berdasarkan taksonomi bloom revisi Anderson. Data penelitian dianalisis secara kualitatif dan kuantitatif.
} 
Berdasarkan hasil analisis secara kuantitatif dapat diketahui bahwa tingkat kesukaran soal kelas X terdapat $71 \%$ soal termasuk kategori sedang dan $29 \%$ soal adalah termasuk kategori mudah. Hasil penelitian dalam pengelompokkan soal berdasarkan ranah kognitif, untuk soal essay didominasi oleh tingkat kognitif $\mathrm{C} 1$ dan C2. Hasil analisis secara kualitatif diperoleh bahwa soal UTS dan UAS kelas X IPA di SMA ittihad Makassar dilihat dari segi tingkat kognitif soal berdasarkan taksonomi bloom revisi Anderson sangat tidak baik, karena sebagian besar butir soal baik itu soal UTS dan UAS tingkat kognitifnya itu kisaran hanya diantar $\mathrm{C} 1, \mathrm{C} 2$ dan $\mathrm{C} 3$. Temuan penelitian ini menunjukkan bahwa masih belum meratanya guru-guru dalam membuat soal-soal berdasarkan ranah kognitif taksonomi bloom pada soal UTS dan UAS Biologi. Hal ini disebabkan karena guru-guru di SMA ittihad Makassar hanya meniru soal dari buku paket ajar sehari-hari tanpa mempertimbangkan jumlah soal pada setiap ranah $\mathrm{C} 1, \mathrm{C} 2, \mathrm{C} 3, \mathrm{C} 4, \mathrm{C} 5$, dan $\mathrm{C} 6$.

Kata kunci: tingkat kesukaran; tingkat kognitif soal; taksonomi bloom revisi anderson

Coresponden Author

Email: ryanhumardani01@gmail.com Artikel dengan akses terbuka dibawah lisensi

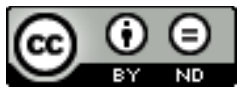

\section{Pendahuluan}

Proses pengajaran merupakan sistem pedoman yang memahami pemahaman sebagai sekumpulan komponen yang saling bergantung untuk mencapai tujuan. Dalam proses pengajaran, sistem hendaknya mencakup tujuan, materi, siswa, guru, metode, situasi dan evaluasi. Untuk mencapai tujuan tersebut, semua komponen yang ada harus diatur agar dapat saling berkolaborasi antar komponen lainnya. Oleh karena itu, guru hendaknya tidak hanya memperhatikan komponen tertentu seperti metode dan materi, tetapi juga memperhatikan komponen tersebut secara keseluruhan. Setiap guru harus memperhatikan semua elemen yang mendukung pembelajaran. Salah satunya adalah penilaian pembelajaran. Evaluasi dalam sistem pendidikan merupakan salah satu kegiatan terpenting yang rutin dilakukan selama kurun waktu tertentu, termasuk pemantauan mutu pendidikan dan pendampingan proses belajar mengajar di kelas (PBM) karena memerlukan alat ukur.

Untuk menilai nilai hasil belajar sebagai prestasi siswa, guru dapat menggunakan tes. Tes merupakan alat ukur, biasanya digunakan untuk mengukur keberhasilan siswa dalam memperoleh kemampuan.

Melihat pentingnya suatu tes dalam upaya untuk mengukur hasil belajar siswa, maka guru seharusnya merancang suatu tes hasil belajar dengan baik dan sesuai dengan tujuan pembelajaran. Dengan demikian item tes harus paralel dengan rumusan indikator hasil belajar. Dengan tes yang baik maka diharapkan siswa juga memperoleh hasil belajar yang baik dan dapat dijadikan tolak ukur keberhasilan dalam dunia pendidikan (Suryani, 2017). 
Percepatan informasi pada masa pendidikan ini seharusnya sesuai dengan kualitas pendidikan terutama kualitas peserta didik. Namun, pada kenyataannya kualitas peserta didik di Indonesia masih rendah. Berdasarkan programme international student assesment (PISA) peringkat indonesia untuk IPA tahun 2015 berada pada urutan 62 dari 70 negara, sedangkan berdasarkan trends in international mathematics and science study (TIMSS) peringkat indonesia untuk sains tahun 2015 berada diurutan 45 dari 48 negara (Kemendikbud, 2018).

Meski kinerja PISA dan TIMSS meningkat pada tahun 2015, Indonesia masih termasuk dalam 10 negara dengan peringkat terbawah. Hal ini dipengaruhi oleh beberapa faktor, antara lain pemahaman guru terhadap kurikulum yang kurang merata, dan tingkat ketidaktahuan guru terhadap kurikulum masih sangat tinggi yaitu 12,8\%. Faktor lain yang juga mempengaruhi adalah masih kurangnya kemampuan siswa Indonesia dalam mengintegrasikan informasi, menarik kesimpulan, dan menghubungkan pengetahuannya dengan hal lain (Rahmawati, 2016).

Dalam taksonomi pendidikan bloom edisi revisi oleh (Anderson \& Krathwohl, 2010) kemampuan mengintegrasikan informasi, menarik kesimpulan dan menghubungkan dengan pengetahuan yang lain dikategorikan dalam kemampuan berfikir tingkat tinggi. Jadi dapat disimpulkan bahwa kemampuan berfikir tingkat tinggi siswa di Indonesia masih rendah.

Hal serupa juga dikemukakan oleh Herlant, Y. dan (Herlant \& Nopithalia, 2007) dalam hasil penelitian mereka tentang kualitas tes buatan guru biologi MTs se-Jakarta selatan diketahui bahwa kemampuan guru dalam membuat soal yang menuntut keterampilan tingkat tinggi masih rendah. Rendahnya kemampuan guru membuat soal kategori keterampilan tingkat tinggi berpengaruh terhadap kemampuan berfikir tingkat tinggi siswa. Hasil penelitian yang dilakukan oleh Nurul Septiana tentang analisis butir soal ulangan akhir semester biologi juga menunjukkan bahwa kemampuan guru dalam membuat soal kategori keterampilan tingkat tinggi masih rendah (Septiana, 2016).

Dalam penelitian yang dilakukan (Kurniawan, 2015), soal yang dijadikan bahan evaluasi pada ujian akhir semester sering kali tidak melalui tahapan analisis kualitas butir soal, sehingga belum diketahui kualitas soal yang telah disusun. Oleh karena itu, untuk mengetahui kualitas butir soal yang digunakan untuk tes perlu dilakukan analisis kualitas butir soal.

Suatu tes dapat dikatakan sahih atau benar jika telah memenuhi kriteria validitas kurikuler yaitu apabila aspek-aspek yang dipersoalkan dalam tes sesuai dengan KD dan indicator (Friatma, 2017). Analisis kurikulum lebih difokuskan pada Kompetensi Dasar (KD) sebagai target spesifik dari kompetensi Inti (KI) yang dijabarkan untuk mencapai indicator (Herlanti, 2015). Sedangkan menurut (Mahirah, 2017), jika instrumen evaluasi kurang baik, maka dapat berakibat hasil evaluasi menjadi kurang baik pula. Namun, apabila instrument evaluasi yang digunakan sudah disusun sesuai dengan semestinya, hal ini dapat berdampak baik. Diantaranya dapat memberikan informasi sejauh mana suatu program berhasil diterapkan, mengetahui kelemahan siswa serta sebab kelemahan 
tersebut dan cara mengatasinya, mendeteksi siswa yang telah dan belum menguasai tujuan pembelajaran dan sebagainya.

Dalam penelitian yang dilakukan oleh (Novi Arti, 2015) tentang kemampuan guru mata pelajaran biologi dalam pembuatan soal higher order thinking (HOT) menjelaskan bahwa kemampuan guru biologi di SMA Negeri 1 Wonosari Klaten dalam membuat soal HOT tingkatan kognitif $\mathrm{C} 4(15,2 \%)$ yang merupakan prosentase tertinggi tingkatan kognitif soal HOT dibanding dengan presentase tingkatan kognitif soal HOT lainnya yaitu tingkatan kognitif C5 dan C6 (3,0\%) karena lebih mudah dalam membuat soal C4 dibandingkan dengan soal C5 dan C6, sedangkan kemampuan guru biologi dalam membuat soal lower order thinking (LOT) pada tingkat kognitif $\mathrm{C} 1 \quad(31,1 \%)$ juga merupakan presentase tertinggi tingkatan kognitif soal LOT dibanding dengan persentase tingkatan kognitif.

Banyak masalah lainnya adalah kognitif level C2 (29,8\%) dan kognitif level C3 $(17,9 \%)$, karena masalah C1 lebih memudahkan guru untuk memudahkan siswa dalam mengerjakannya, namun hal ini akan menyebabkan siswa hanya menghafal materi untuk mencapai yang baik. Prestasi mengurangi rasa ingin tahu siswa dan mengurangi kemampuan siswa untuk menciptakan hal-hal baru. Pada tingkat kognisi C1, pertanyaan ulangan harian guru mendominasi, yang akan mengarah pada kemampuan siswa untuk menciptakan hal-hal baru untuk penelitian sekolah menengah. Menurut penjelasan guru tersebut, soal ujian tengah semester (UTS) dibuat sendiri oleh guru bidang studi biologi sedangkan soal ujian akhir semester (UAS), Musyawarah Guru Mata Pelajaran (MGMP) Dinas Pendidikan setempat namun juga ada soal UAS yang dibuat sendiri oleh guru bidang studi biologi sendiri yang sebagian besar soal tes tersebut masih mencakup tingkat kognitif C1-C4.

Meskipun masalah memori dan pemahaman merupakan dasar dari pemikiran tingkat tinggi, perkembangan masalah memori terlalu berlebihan dan tidak dapat diimbangi dengan masalah kognitif tingkat tinggi.Hal ini akan berdampak buruk, karena bagaimanapun juga masalah yang berkontribusi pada proses pembelajaran sangat diakui. Mengetahui masalahnya. Beberapa pertanyaan guru yang memerlukan pemikiran lanjutan menunjukkan bahwa pelajaran sains di sekolah belum melatih siswa untuk mengembangkan kemampuan berpikir dan bernalar. Hasil ini juga menunjukkan bahwa keterampilan bertanya guru masih perlu ditingkatkan.

Berdasarkan pemikiran tersebut, maka penulis tertarik untuk melakukan penelitian dengan judul: "identifikasi soal tes ujian tengah semester (UTS) dan ujian akhir semester (UAS) mata pelajaran biologi berdasarkan taksonomi bloom revisi Anderson terhadap pemahaman konsep pembelajaran siswa kelas X SMA ittihad Makassar'’.

Penelitian ini bertujuan untuk mengetahui kualitas tingkat kesukaran dan kognitif butir soal UTS dan UAS biologi buatan guru-guru kelas X di SMA ittihad Makassar.

\section{Metode Penelitian}

Penelitian ini menggunakan metode deskripsi kuantitatif. Rancangan penelitian menggunakan soal tes UTS dan UAS pada mata pelajaran Biologi kelas X IPA SMA 
Ittihad Makassar, berdasarkan format soal (format makalah) dan klasifikasi Bloom revisi Anderson (aspek kognitif C1, C2, C3, C4, C5 dan C6 Caranya adalah dengan mencatat soal-soal tes yang dikelompokkan berdasarkan UTS dan UAS, kemudian mengidentifikasi soal-soal tes tersebut berdasarkan dimensi kognitif dari soal-soal tes tersebut berdasarkan klasifikasi Bloom yang direvisi Anderson. Populasi penelitian ini berdasarkan soal tes UTS dan UAS pada mata pelajaran biologi berdasarkan klasifikasi Bloom revisi Anderson dari SMA Ittihad Makassar.

Berdasarkan klasifikasi kelas X IPA SMA Ittihad Makassar Bloom revisi Anderson, soal tes UTS dan UAS pada mata pelajaran biologi yang diperoleh adalah sampel. Alat pengumpulan data menggunakan soal tes UTS dan UAS, angket, wawancara dan dokumen. Dengan menggunakan program Anates, penggunaan teknik analisis data untuk mengukur kesulitan soal tes UTS dan UAS, dan pada saat yang sama, menurut metode klasifikasi Bloom yang direvisi Anderson, dengan mengelompokkan soal tes sesuai dengan level yang ditentukan untuk mengukur tingkat kognitif masalah. Klasifikasi Bloom yang direvisi Anderson, yaitu: pertanyaan level, menurut klasifikasi Bloom yang direvisi dari Anderson untuk item tinggi dan rendah.

\section{Hasil dan Pembahasan}

Penelitian ini dilakukan dengan tujuan untuk mengetahui kulaitas butir soal dilihat dari tingkat kesukaran dan kognitif soal berdasarkan taksonomi bloom revisi Anderson pada kelas X SMA di SMA ittihad Makassar. Soal yang dianalisis pada penelitian ini berupa soal essay ujian tengah semester (UTS) dan ujian akhir semester (UAS) tahun ajaran 2018-2019.

\section{Tingkat Kesukaran Soal Berdasarkan Taksonomi Bloom Revisi Anderson}

Perhitungan indeks kesukaran dilakukan dengan program Anates. Hasil perhitungan indeks kesukaran tersebut di interpretasikan dalam tiga kriteria yaitu:

a. P : 0,00-0,30 adalah soal yang tergolong sulit.

b. P : 0,31-0,70 adalah soal yang tergolong sedang.

c. P : 0,71-1,00 adalah soal yang tergolong mudah

Hasil analisis tingkat kesulitan dapat digambarkan pada tabel berikut ini:

Tabel 1

Tingkat Kesulitan Soal UTS Mata Pelajaran Biologi Kelas X

\begin{tabular}{ccc}
\hline Nomor Soal & Hasil & Kategori Tingkat Kesukaran \\
\hline 1 & 0,71 & Mudah \\
\hline 2 & 0,68 & Sedang \\
\hline 3 & 0,57 & Sedang \\
\hline 4 & 0,60 & Sedang \\
\hline 5 & 0,58 & Sedang \\
\hline 6 & 0,60 & Sedang \\
\hline 7 & 0,73 & Mudah \\
\hline 8 & 0,63 & Sedang \\
\hline 9 & 0,45 & Sedang \\
\hline 10 & 0,58 & Sedang \\
\hline
\end{tabular}


Data pada tabel 1 diatas menunjukkan bahwa soal essay berkategori mudah sebanyak 2 butir soal dan berkategori sedang sebanyak 8 butir soal Tingkat kesukaran soal ditinjau dari kemampuan siswa mengerjakan soal tersebut.

Soal yang baik adalah soal yang memiliki tingkat kesukaran sedang. Soal yang terlalu mudah tidak merangsang kemampuan berpikir siswa dan tidak memberikan motivasi positif bagi siswa. Sebaliknya, soal yang terlalu sukar akan membuat siswa tidak mau mencoba lagi dan merasa frustasi bagi siswa yang memiliki motivasi belajar rendah (Syamsudduha, 2012).

Tabel 2

Tingkat Kesukaran Soal UAS Mata Pelajaran Biologi Kelas X

\begin{tabular}{ccc}
\hline Nomor Soal & Hasil & Kategori tingkat kesukaran \\
\hline 1 & 0,66 & Sedang \\
\hline 2 & 0,62 & Sedang \\
\hline 3 & 0,50 & Sedang \\
\hline 4 & 0,55 & Sedang \\
\hline 5 & 0,66 & Sedang \\
\hline 6 & 0,57 & Sedang \\
\hline 7 & 0,52 & Sedang \\
\hline 8 & 0,63 & Sedang \\
\hline 9 & 0,62 & Sedang \\
\hline 10 & 0,61 & Sedang \\
\hline
\end{tabular}

Berdasarkan tabel di atas dapat dijelaskan bahwa semua permasalahan UAS termasuk dalam kategori sedang. Kesulitan soal adalah proporsi peserta tes yang menjawab soal dengan benar. Tingkat kesulitan proyek biasanya diwakili oleh $\mathrm{p}$. Semakin besar nilai $\mathrm{p}$, semakin besar proporsi jawaban benar untuk item tersebut, dan semakin rendah tingkat kesulitan item tersebut, yang berarti masalah tersebut lebih mudah untuk diselesaikan.

Soal yang baik adalah soal yang tidak terlalu mudah atau tidak terlalu sukar. Soal yang terlalu mudah tidak merangsang siswa untuk mempertinggi usaha memecahkannya. Sebaliknya soal yang terlalu sukar akan menyebabkan siswa menjadi putus asa dan tidak mempunyai semangat untuk mencoba lagi karena di luar jangkauannya (Arikunto, 1992).

Menggunakan program Anates untuk menghitung tingkat kesulitan soal ujian tengah semester (UTS) dan ujian akhir semester (UAS) SMA Ittihad Makassar Kelas X IPA Biologi. Hasil perhitungan program Anates berbentuk persentase, sehingga perlu diubah menjadi angka desimal. Selain itu, dijelaskan dengan menggunakan standar berikut. Soal P 0,00 sampai 0,30 merupakan soal yang sulit, soal P 0,31 sampai 0,70 merupakan soal sedang, dan soal P 0,71 sampai 1,00 merupakan soal yang mudah. Berdasarkan hasil analisis 10 soal UTS nomor X soal, 8 atau $80 \%$ soal termasuk 
kategori sedang, 2 atau 20\% soal termasuk kategori sederhana, dan UAS termasuk 10 dari 10 soal. tipe $\mathrm{X}$ atau $100 \%$ soal termasuk dalam kategori sedang.

Dengan demikian, dapat disimpulkan bahwa Ujian Akhir (UAS) tingkat X SMA Ittihad Makassar merupakan soal dengan tingkat kesukaran sangat rendah karena semua butir soal atau $100 \%$ bersertifikasi sedang. Sementara untuk Ujian Tengah Semester (UTS) Kategori X, soal-soal yang ada juga termasuk dalam kategori kurang baik. Karena kategori soal tidak jauh berbeda dengan soal UTS, maka yang terbaik adalah menggunakan soal dengan tingkat kesulitan yang seimbang, yaitu: $25 \%$ soal kategori sulit, 50\% soal kategori sedang, dan 25\% kategori sederhana.

Walaupun demikian menurut Mustarah dalam penelitiannya (2013) bahwa soalsoal yang dianggap baik adalah soal-soal yang sedang, yaitu soal-soal yang mempunyai indeks kesukaran berkisar antara 0,26-0,75. Berbagai kriteria tersebut mempunyai kecenderungan bahwa butir soal yang memiliki indeks kesukaran kurang dari 0,25 dan lebih dari 0,75 sebaiknya dihindari atau tidak digunakan, karena butir soal yang demikian terlalu sukar atau terlalu mudah, sehingga kurang mencerminkan alat ukur yang baik.

Namun demikian menurut (Arifin, 2009) soal-soal yang terlalu mudah atau terlalu sukar tidak berarti tidak boleh digunakan. Hal ini tergantung dari tujuan penggunaannya. Jika dari peserta tes banyak, padahal yang dikehendaki lulus hanya sedikit maka diambil peserta yang terbaik, untuk itu diambilkan butir soal tes yang sukar. Demikian sebaliknya jika kekurangan peserta tes, maka dipilihkan soal-soal yang mudah. Selain itu, soal-soal yang sukar akan menambah motivasi belajar bagi siswa-siswa yang pandai, sedangkan soal-soal yang mudah akan membangkitkan semangat kepada siswa yang lemah

2. Tingkatan Kognitif Soal Berdasarkan Taksonomi Bloom Revisi Anderson

\section{Tabel 3}

Pengelompokkan Butir Soal UTS Kelas X IPA Berdasarkan Tingkatan Kognitif Taksonomi Bloom Revisi Anderson

\begin{tabular}{cccccccc}
\hline & & \multicolumn{6}{c}{ Tingkatan kognitif Taksonomi Bloom Revisi Anderson } \\
\cline { 3 - 8 } Sumber & Jumlah & C1 & C2 & C3 & C4 & C5 & C6 \\
\hline KELAS & 10 & 5 & 4 & 1 & - & - & - \\
\cline { 2 - 8 } X & $100 \%$ & $50 \%$ & $40 \%$ & $10 \%$ & - & - & - \\
\hline
\end{tabular}

Hasil penelitian mengelompokkan soal berdasarkan ranah kognitif, untuk soal essay didominasi oleh tingkat kognitif C1 dan C2. Soal UTS kelas X terdapat 5 (50\%) soal tingkatan mengingat (C1), 4 (40\%) soal tingkatan memahami (C2), dan $1(10 \%)$ soal tingkatan menerapkan (C3). 
Tabel 4

Pengelompokkan Butir Soal UAS Kelas X IPA Berdasarkan Tingkatan Kognitif Taksonomi Bloom Revisi Anderson

\begin{tabular}{cccccccc}
\hline & & \multicolumn{5}{c}{ Tingkatan kognitif Taksonomi Bloom Revisi Anderson } \\
\cline { 3 - 7 } Sumber & Jumlah & $\mathrm{C} 1$ & $\mathrm{C} 2$ & $\mathrm{C} 3$ & $\mathrm{C} 4$ & $\mathrm{C} 5$ & C6 \\
\hline KELAS & 10 & 3 & 5 & 2 & - & - & - \\
\cline { 2 - 7 } X & $100 \%$ & $30 \%$ & $50 \%$ & $20 \%$ & - & - & - \\
\hline
\end{tabular}

Hasil penelitian mengklasifikasikan masalah UAS berdasarkan ranah kognitifnya, karena soal makalah terutama ditentukan oleh tingkat kognitif $\mathrm{C} 1$ dan $\mathrm{C} 2$. Pada kategori X soal UAS, level memori (C1) ada 3 (30\%) soal, level pemahaman (C2) punya $5(50 \%)$ soal, dan level aplikasi (C3) punya 2 (20\%) soal).

Berdasarkan tabel di atas dapat disimpulkan bahwa pada taraf kognitif, soal UTS dan UAS IPA tipe X SMA Ittihad Makassar kurang baik pada taraf kognitif, karena berdasarkan revisi taksonomi Bloom dari Anderson, permasalahan tersebut adalah Tidak terlalu baik, baik masalah UTS maupun UAS tingkat kognitifnya hanya berada di antara C1, C2 dan C3, yang menunjukkan bahwa masalah tersebut tidak dapat menumbuhkan kemampuan berpikir siswa, juga tidak dapat digunakan sebagai acuan untuk mengevaluasi siswa. kemampuan. Jadi masalahnya perlu diselesaikan.

Alasan tidak meratanya ranah kognitif Taksonomi Bloom pada soal UTS dan UAS Biologi disebabkan karena gurunya hanya meniru soal dari buku paket ajar sehari-hari tanpa mempertimbangkan jumlah soal pada setiap ranah $\mathrm{C} 1, \mathrm{C} 2, \mathrm{C} 3, \mathrm{C} 4$, C5, dan C6.

Berdasarkan hasil wawancara dan angket yang dilakukan dengan guru Biologi IPA level X bidang kognitif SMA Ittihad Makasar, untuk soal UTS level X hanya C2 yang tercapai, sedangkan soal level UAS X hanya mencapai C3. Ajukan pertanyaan, Namun harus pada jenjang SMA, soal standar harus mencakup bidang C1, C2, C3, C4 hingga $\mathrm{C} 5$, bahkan sampai pada tingkat kognitif (C6), sehingga dapat digunakan untuk kemampuan berpikir dan membuat siswa. pengukuran kemampuan siswa lebih terkonsentrasi dan akurat. Rasio pertanyaan yang benar adalah $30 \%$ untuk $\mathrm{C} 1$ dan $\mathrm{C} 2$, $40 \%$ untuk C3 dan C4, dan 30\% untuk C5 dan C6.

Berdasarkan penelitian (Ainul Uyuni, 2015), adapun tahapan-tahapan yang harus dilakukan untuk memenuhi kategori yang baik adalah, memperbaiki tes, yaitu memperbaiki soal sesuai dengan saran-saran dari guru maupun validator ahli serta berdasarkan hasil analisis uji coba terhadap tes yang masih belum memenuhi kriteria sebagai tes yang baik. Merakit tes yaitu menyusun kembali soal yang telah diperbaiki/direvisi setelah uji coba, dengan demikian dihasilkan sebuah tes kognitif yang dapat digunakan untuk mengukur kemampuan siswa dan telah diuji kualitasnya.

Selain itu, tahap sosialisasi dilakukan dengan menyebarluaskan tes perkembangan kognitif kepada anggota forum MGMP Bio Makassar (Theme Teacher Meeting) yang diadakan di Sekretariat MGMP Bio Makassar SMA Negeri 5 Makassar. Pembagian ini dilakukan agar tes yang dikembangkan dapat digunakan secara lebih luas untuk mengukur kemampuan siswa dalam menyerap materi. 


\section{Kesimpulan}

Berdasarkan hasil analisis dan pembahasan yang telah dikemukakan, serta ungkapan pertanyaan referensi penelitian, dapat ditarik beberapa kesimpulan yaitu berdasarkan hasil analisis masalah X tipe 10 UTS. Angka, kategori sedang berisi $8 \%$ atau $80 \%$ pertanyaan, dan kategori berisi $2 \%$ atau $20 \%$ pertanyaan. Mudah. Untuk soal UAS kategori X, dari 10 soal, $10 \%$ atau $100 \%$ soal termasuk dalam kategori sedang. Soal level memori (C1) sebanyak 5 (50\%), soal level pemahaman (C2) sebanyak 4 (40\%), dan soal level aplikasi (C3) sebanyak 1 (10\%). Meskipun masalah UAS didasarkan pada domain kognitif, untuk tesis masalah tersebut terutama ditentukan oleh tingkat kognitif $\mathrm{C} 1$ dan C2. Pada kategori X soal UAS, level memori (C1) ada 3 (30\%) soal, level pemahaman (C2) punya 5 (50\%) soal, dan level aplikasi (C3) punya 2 (20\%) soal). 
Ryan Humardani Syam Pratomo dan Sri Mukminati Nur

\section{BIBLIOGRAFI}

Ainul Uyuni, Taufiq. (2015). Pengembangan Tes Kognitif Berbasis Revisi Taksonomi Bloom Pada Materi Sistemreproduksi Untuk Siswa Sma. Jurnal Biotek, 3(2), 1-17.

Anderson, Lorin W., \& Krathwohl, David R. (2010). Kerangka Landasan Untuk Pembelajaran, Pengajaran, Dan Asesmen. Yogyakarta: Pustaka Pelajar, 300(300), 0 .

Arifin, Zainal. (2009). Evaluasi Pembelajaran. Bandung: Pt Remaja Rosdakarya.

Arikunto, Suharsimi. (1992). Prosedur Penelitian: Suatu Pendekatan Praktik. Rineka Cipta.

Friatma, Ayunda. (2017). Analisis Kualitas Soal Ujian Akhir Semester Genap Mata Pelajaran Biologi Kelas Xi Ipa Sma Negeri Wilayah Selatan Kabupaten Solok Tahun Pelajaran 2015/2016. Universitas Negeri Padang.

Herlant, Y., \& Nopithalia, N. (2007). Meneropong Kualitas Soal Tes Buatan Guru Biologi Mts Negeri Se-Jakarta Selatan. Meneropong Kualitas Soal Tes Buatan Guru Biologi Mts Negeri Se-Jakarta Selatan.

Herlanti, Y. (2015). Analisis Domain Pengetahuan Dan Kognitif Pada Kurikulum Indonesia Tahun 1984-2013 Mata Pelajaran Biologi Sekolah Menengah Atas. Seminar Nasional Xii Pendidikan Biologi Fkip Uns, 304-308.

Kemendikbud, Pdspk. (2018). Profil Sistem Zonasi Penerimaan Peserta Didik Baru Dan Zonasi Mutu Pendidikan. Kemendikbud Ri, 24.

Kurniawan, Tutut Kurniawan. (2015). Analisis Butir Soal Ulangan Akhir Semester Gasal Mata Pelajaran Ips Sekolah Dasar. Journal Of Elementary Education, 4(1), 1-6.

Mahirah, B. (2017). Evaluasi Belajar Peserta Didik (Siswa). Idaarah: Jurnal Manajemen Pendidikan, 1(2).

Novi Arti, Endah Putri. (2015). Kemampuan Guru Mata Pelajaran Biologi Dalam Pembuatan Soal Hot (Higher Order Thinking) Di Sma Negeri 1 Wonosari Klaten. Universitas Muhammadiyah Surakarta.

Rahmawati. (2016). Seminar Hasil Timss 2015 Diagnosa Hasil Untuk Perbaikan Mutu Dan Peningkatan Capaian, (Naskah Presentasi Yang Disajikan Pada Seminar Hasil Penilaian Pendidikan Oleh Kementerian Pendidikan Dan Kebudayaan. Prosiding Seminar Nasional Indocompac.

Septiana, Nurul. (2016). Analisis Butir Soal Ulangan Akhir Semester (Uas) Biologi Tahun Pelajaran 2015/2016 Kelas X Dan Xi Pada Man Sampit. Edu Sains: Jurnal Pendidikan Sains Dan Matematika, 4(2). 
Identifikasi Soal Tes UTS dan UAS Mata Pelajaran Biologi Berdasarkan Taksonomi Bloom Revisi Anderson terhadap Pemahaman Konsep Pembelajaran

Suryani, Yulinda Erma. (2017). Pemetaan Kualitas Empirik Soal Ujian Akhir Semester Pada Mata Pelajaran Bahasa Indonesia Sma Di Kabupaten Klaten. Jurnal Penelitian Dan Evaluasi Pendidikan, 21(2), 142-152.

Syamsudduha, St. (2012). Penilaian Kelas. Makassar: Alauddin Press. 